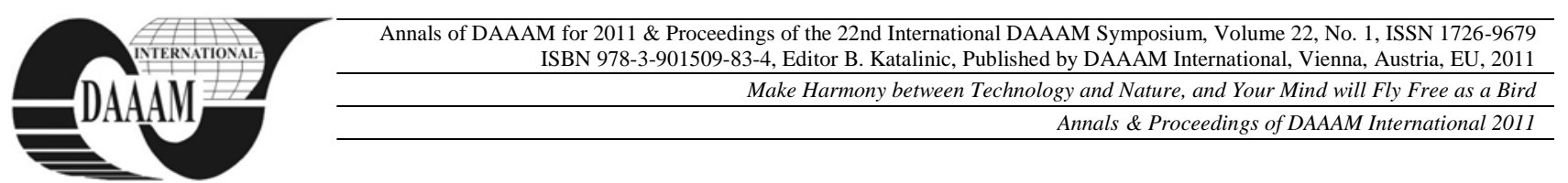

\title{
PERFORMANCE MEASUREMENT REVIEW
}

\author{
KATIC, D[ragan]; MAJSTOROVIC, V[lado] \& COLAK, I[vo]
}

\begin{abstract}
This paper describes shortly overview of the area of performance measurement. It describes the definitions, concepts and relationships between performance management and performance measurement. The improvement of the business company is based on a performance measurement system that is at the core of the performance management and is essential for its efficient use. Performance measurement is the finding how the organization achieves progress toward long-term goals set and achieved the mission and vision.

Key words: performance measurement, performance management, business improvement, business strategy
\end{abstract}

\section{INTRODUCTION}

Performance measurement and productivity has a significant interest in recent years among both academics and practitioners (Tangen, 2004). The subject of performance measurement is vast and numerous authors continuously add to the body of literature on the subject.

The question is why the performance measurement has become such an important topic in recent years. It is impossible to answer this question, but obviously there are at least seven reasons (Neely, 1999):

- the changing nature of work,

- increasing competition,

- specific improvement initiatives,

- national and international awards,

- changing organizational rules,

- changing external demands,

- the power of information technology.

Most authors agree that manager's measure for two main reasons. Either they want to know where they are and what they have to improve or they want to influence their subordinate's behavior (Beatham at al., 2004.).

The traditional view of performance measurement is an integral element of planning and control. It is assumed that the measurement provides a means of capturing performance data that can be used for decision making. This mechanistic view is complementary to the widespread opinion that the performance measurement has an impact on organizational behavior.

Organizations traditionally have measured their performance solely in financial terms. This limited approach is not sufficient because it show the results of decisions made in paste, have no impact on improving current performance and don't show causes of such results. It is very important to see how to measured organizational performance, as has the impact on market share, so this may be accepted from potential investors, employees and customers. For these, the most important is system that represents balance between financial score and drivers for further performance.

As a result of the limitations of traditional performance measurement models, new performance measurement models have been developed in order to respond modern business requirements.
Features of these new models are the connection with corporate strategies and the development of no financial measures. New models of performance measurement can be grouped into the following groups:

- Models that emphasize self-assessment: the Deming Prize, the Baldridge Award, the EFQM Excellence Model.

- Models that are designed to assist management and improve business processes: Capability Maturity Matrices, the Performance Pyramid, the Effective Progress and Performance Measurement $\left(\mathrm{EP}^{2} \mathrm{M}\right)$ and the Balanced Scorecard (BSC).

Common to these new integrated model or framework is trying to determine a stronger connection the performance measurement with strategy and long-term vision. Performance measurement models encourage continued progress and control the balance between short-and long-term goals, financial and no financial measures, and external and internal performance.

The new research's area has been developed, whose objectives were to identify the correct number and types of performance measures in ways that are integrated into company strategy. Substantial progress in the understanding of performance measurement is shown in the work of Kaplan and Norton (1992). They watch the performance through a wider range of perspectives, not only through financial measures, establishing a balanced set of measures to control key business processes.

The BSC helps organizations to effectively measure of organizational performance, increasing intangible assets and implementation strategies through financial and no financial measures.

\section{PERFORMANCE MEASUREMET CONCEPT}

The research in the area of performance measurement demonstrates the inconsistency and lack of definitions and terms (O'Donnell \& Duffy's, 2002). Many published papers are directly addressed on the area of performance but does not explicitly define the performance itself. Some terms such as efficiency and effectiveness often appear in the reviewed works, although not used specifically to define the performance. Generally, the effectiveness associated with achieving goals while efficiency is related to the utilization of resources. Although the effectiveness and efficiency used to describe the performance, the correlation between these two elements is not defined.

Overall, the research in performance is hampered by the lack of clarity of these terms, especially because (O'Donnell \& Duffy's, 2002):

- The key elements of performance have not been consistently defined or agreed.

- Those defining performance as efficiency and effectiveness have not distinguished them clearly or related them within a formalism of performance.

- Many of the measures used in the research relate to influences on performance and not performance itself. 
Performance management is the process by which the leadership of the company adjusts its performance with corporate and functional strategies and goals. The goal of this process is to enable proactive control loop where the corporate and functional strategies explained in the business processes, activities, tasks and staff (Bititci at al., 1997). Feedback allows proper management of decisions.

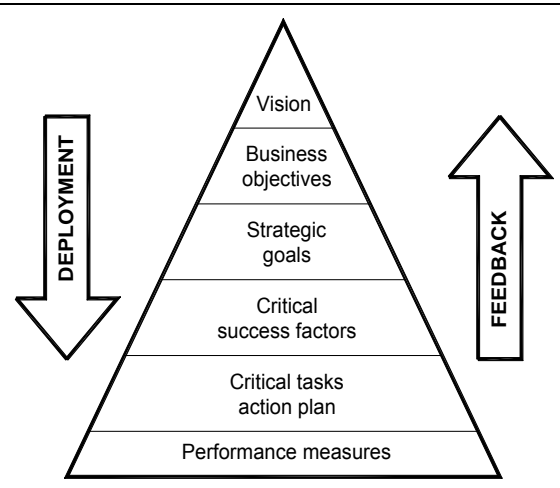

Fig. 1. The closed loop deployment and feedback system for the performance management process (Bititci at al., 1997)

Kagioglou at al. (2001) defines performance management as a closed control system that implements the strategy and policy, and accepts feedback from various levels in order to control performance of the system. Performance measurement system is an information system that is at the heart of the performance management process and is critical for effective and efficient functioning of the performance measurement system. Performance measurement is the process of determining how successful organizations or individuals in achieving their goals or strategies.

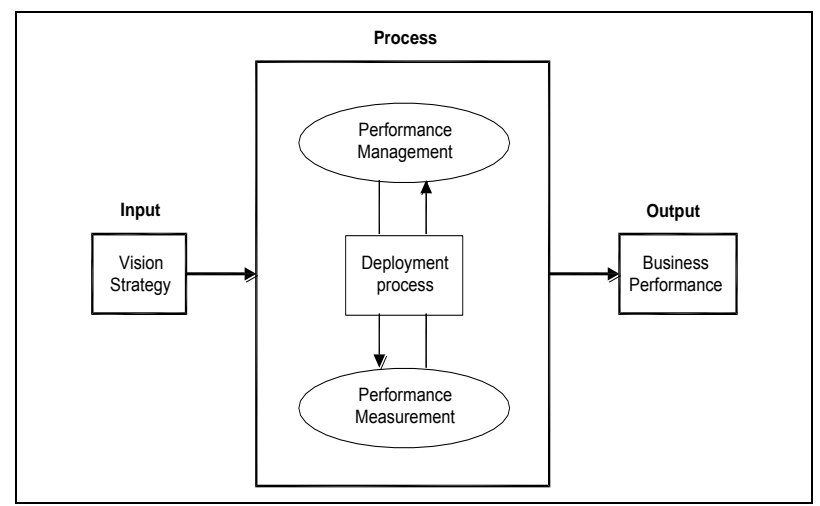

Fig. 2. The performance management/measurement process (Kagioglou at al., 2001)

Amaratunga et al. (2001) describes performance measurement as a process of assessing progress in achieving the set goals, including information on resource efficiency, the quality of results and effectiveness of organizational operations and their contribution to achieving organizational goals. On the other hand the performance management is to use information from performance measurement to act positively to changes in organizational culture, systems and processes, helping to establish a set of performance goals, allocating and prioritizing among the resources, informing managers to confirm or change current policy or guidance in achieving goals, and sharing the results of performance in implementing the goals.

According to Nelly et al. (2005) performance measurement is part of the process of strategic control. Therefore, follows that for performance measurement exist certain rules as well as strategic control. Performance measurement is a process of quantifying action, where the measurement process of quantifying the mutual actions related to performance.
The reviewed works in the field of performance measurement shows that most publications examines the relationship between strategy and performance measurement of what is considered the central theme of this area. It can be seen that the performance measurement is part of the business improvement process. Therefore, performance measurement should be part of a system that monitors performance, decide on actions and changes in business operations.

Although the concept of performance management as a key business processes, young discipline, it begins to define a performance management system that will ensure the future well-being and prosperity of any organization. A key part of performance management is to use the results of measurements to aid decision making. Defining and monitoring indicators, the lack of data, time and money just from some of the most important obstacles in implementing performance management systems.

\section{CONCLUSION}

In an effort to maintain and improve the competitive advantage of organizations performance measurement is widely used for evaluating, controlling and improving business processes. Research shows that traditional performance measurement based on the financial apparatus is not appropriate. Also, there are some limitations of the traditional production management related to increasing productivity, reducing costs and increasing profits, which may reduce the improvement of quality, reliability and delivery, shorten lead times, and reduce capacity and efficient development of capital.

This paper briefly describes the basic definitions and concepts of performance measurement. It is important for any organization to benchmarking of its results with the best in the industry to identify and define improvement measures.

\section{REFERENCES}

Amaratunga, D.; Baldry, D. \& Sarshar, M. (2001). Process improvement through performance measurement: the balanced scorecard methodology. An International Journal, Vol. 50, No. 5, 2001, pp179-188, ISSN 1463-5771

Beatham, S.; Anumba, C. \& Thorpe, T. (2004). KPIs: a critical appraisal of their use construction. An International Journal, Vol. 11, No. 1, 2004, pp 93-117, ISSN 1463-5771

Bititci, U. S.; Carrie, A. S. \& McDevitt, L. (1997). Integrated performance measurement systems: a development guide. International Journal of Operations \& Production Management, Vol. 17, No. 5, 1997, pp 522-534, ISSN 0144-3577

Kagioglou, M.; Cooper, R. \& Aouad, G. (2001). Performance management in construction: a conceptual framework. Construction Management and Economics, Vol. 19, No. 1, January 2001, pp 85-95, ISSN 0144-6193

Neely, A. (1999). The performance measurement revolution: why now and what next? International Journal of Operations\& Production Management, Vol. 19, No. 2, 1999, pp 205-228, ISSN 0144-3577

Nelly, A.; Gregory, M. \& Platts, K. (2005). Performance measurement system design: a literature review and research agenda. International Journal of Operations \& Production Management, Vol. 25, No. 12, 2005, pp 12281263, ISSN 0144-3577

O'Donnell, F.J. \& Duffy, A.H.B. (2002). Modeling design development performance. International Journal of Operations \& Production Management, Vol. 22, No. 11, 2002, pp 1198-1221, ISSN 0144-3577

Tangen, S. (2004). Performance measurement: from philosophy to practice. International Journal of Productivity and Performance management, Vol. 53, No. 8, 2004, pp 726737, ISSN 1741-0401 